\title{
SEASONAL BREEDING OF FREE-RANGING RHESUS MONKEYS AND RELATED ECOLOGICAL FACTORS
}

\author{
JOHN G. VANDENBERGH* AND STEPHEN VESSEY \\ Laboratory of Perinatal Physiology, National Institute of Neurological Diseases and \\ Blindness, National Institutes of Health, Public Health Service, \\ United States Department of Health, Education and Welfare, San Juan, Puerto Rico
}

(Received 14th November 1966)

\begin{abstract}
Summary. The seasonal appearance of mating activities and births of rhesus monkeys in a free-ranging colony on two small islands near La Parguera, Puerto Rico, were recorded from the founding of the colony in 1962 to August 1966. Mating activities began in late August or September, reached a peak during November and December, and ceased in March or April. Except for a wide spread early in the colony's history, births were confined to the period from March to July, with $74 \%$ occurring during May and June. Lactating females began mating activities later than non-lactating females. The onset of mating typically followed vegetation changes associated with a period of high rainfall in late summer. The correlation between rainfall and mating activities, perhaps resulting from vegetational changes, also appears to be present at Cayo Santiago, another island colony of monkeys, and in Northern India, the natural home of the rhesus monkey.
\end{abstract}

\section{INTRODUCTION}

The seasonal pattern of breeding seen in many wild animals has long been known to synchronize with seasonal changes in the environment and, in a number of cases, the specific environmental changes to which a particular species responds have been identified experimentally. Once a specific environmental change has been isolated the physiological mechanisms responsive to the change can be investigated.

Birds living in the temperate zone provide the best examples of species that have been studied in the above manner. Rowan (1925) isolated changes in daylength as the critical environmental factor stimulating breeding in starlings. Rowan's discovery has been confirmed and extended to a number of other temperate zone birds (Farner, 1959; Marshall, 1961). Experiments conducted on the physiological responses associated with photoperiodic stimulation have indicated the importance of the hypothalamo-hypophysial neurosecretory system in stimulating endocrine changes associated with breeding (Oksche, Laws, Kamemoto \& Farner, 1959). Thus, in many birds the chain of events connecting an environmental change with the onset of breeding is quite well known.

* Present address: Dorothea Dix Hospital, Raleigh, North Carolina 27602, U.S.A. 
In arid and semi-arid areas of the world rainfall, rather than photoperiod, appears to act as a stimulus to breeding. The breeding activity of many Australian birds follows acyclic changes of rainfall rather than changes in photoperiod (Serventy \& Marshall, 1957). Rising water levels resulting from distant rainfall correlate well with the onset of breeding in some Australian ducks (Frith, 1959). Weaver finches in Tanganyika have also been shown to breed following events associated with rainfall (Marshall \& Disney, 1957). Breeding activity associated with rainfall or vegetational changes is not limited to southern hemisphere birds. Orians (1960) described extensive autumnal breeding in colonies of tricoloured blackbirds in irrigated areas of California.

Among mammals, the relationship between environment and seasonal breeding is still poorly understood. Few species have been studied in detail and all are residents of the temperate zone. Again, photoperiodic changes appear to play the dominant role. Artificial changes in day-length influence the timing of breeding in the vole (Baker \& Ranson, 1932), raccoon (Bissonnette \& Csech, 1930) and mustelids (Bissonnette, 1932). The seasonal breeding of the rabbit, Oryctolagus cuniculus, in Australia, has been studied in considerable detail and Poole (1960) concludes that seasonal increases in fertility of both males and females show a close relationship to increases in rainfall and associated vegetation changes. Among primates there is a great dearth of information; in fact, it has been recognized only recently that many primate species breed with a seasonal rhythm (Lancaster \& Lee, 1965).

The primary purpose of this study was to examine environmental factors on two small islands at La Parguera, Puerto Rico, containing free-ranging rhesus monkeys (Macaca mulatta), in an attempt to correlate observed environmental changes with the breeding activities of the monkeys. Secondarily, comparisons were drawn between these findings and the available information on rhesus monkeys living under different environmental conditions.

\section{STUDY AREA, SUBJECTS AND METHODS}

Two islands, La Cueva and Guayacan, lie directly off the arid south-western coast of Puerto Rico near the village of La Parguera. These islands, together containing approximately 190 acres of dry land and mangrove swamp, were populated with twenty-three rhesus monkeys transferred from another island colony, Cayo Santiago, and with 255 newly-imported monkeys from India. The bulk of the animals were released in 1962 and a few were released in late 1961 and 1963. Many of the Indian importees died soon after arrival and others were removed for use in experimental settings. The survivors, plus the monkeys born on the islands, totalled 189 animals by August 1966. Each monkey was tattooed upon release or within 1 year of birth to permit recognition in the field. The supply of naturally occurring food and water on the islands was insufficient to maintain the population and a constant supply of Purina Monkey Chow and water was provided at a number of locations. A more complete description of the habitat and the monkeys is presented by Vandenbergh (1967).

The methods used in this study were primarily directed towards gathering information on environmental changes and on breeding activities. Changes in vegetation were measured by bi-monthly examination of forty-six individual 
plants comprising twenty-three species: a grass, fifteen shrubs and seven trees. The presence of new leaves, flowers or fruit was recorded at each examination. Standard daily climatic measurements were made of rainfall, temperature and relative humidity.

Between September 1962 and August 1966, two basic measures of the monkeys' breeding activities were made: frequency of mating behaviour and incidence of births. Mating behaviour was recorded by three individuals during approximately $1500 \mathrm{hr}$ of observation. Observations were conducted each month during the 4-year period of this study with the lowest monthly total being $19 \mathrm{hr}$ and the average $32 \mathrm{hr}$. The techniques used to observe the monkeys are described by Vandenbergh (1967) and for the purpose of this report only observations of mating behaviour will be presented.

To measure changes in the frequency of sexual behaviour from month to month the following activities were recorded during each observation session: consorts, serial mounts and copulations. Consort behaviour is defined as a close association of an adult male and an oestrous female during which, following mutual grooming, mounting and copulation are typically seen. These behaviour patterns are well described by Carpenter (1942) and Altmann (1962). Mounting, in rhesus monkeys, apparently performs a social as well as a sexual function (Hinde \& Rowell, 1962) and for this reason isolated mounts were not used as a measure of sexual activity. To eliminate the possibility that 'social' mounts could be confused with 'sexual' mounts, only mounts seen to occur in series were counted, i.e. repeated mounts, at least one every $5 \mathrm{~min}$, of an individual female by the same male were recorded as one serial mount. Such serial mounts often ended in ejaculation as characterized by rigidity of the male during a prolonged pelvic thrust. In addition, copulation could also be confirmed as the pair separated because ejaculation resulted in a visible overflow of semen in the female's vulva. This overflow, or 'plug', immediately coagulated and often remained with the female for 12 to $24 \mathrm{hr}$. If a female was seen with such a 'plug' even though the male was not present, copulation was considered to have occurred.

Each consort, serial mount or copulation observed was recorded and given a numerical value of 1 . However, if a female was seen repeatedly in consort with a specific male during a single day, only one consort was recorded. If, as rarely occurred, a female consorted with more than one male during a day, each consort was recorded separately. To permit comparisons from month to month, the frequency of consorts, serial mounts and copulations during each month were totalled and then divided by the number of adult females in the colony and the total number of hours of observation. The resulting number times 100 yielded a 'Mating Index.'

Data were collected on the incidence of births by making daily attempts to view each female judged to be near term. With very few exceptions birth dates were noted within 1 to 2 days.

\section{RESULTS}

Mating activities appeared with seasonal rhythmicity in the La Parguera colony (Text-fig. 1). Mating was already underway in September 1962 when 
detailed observations were first made. By April, however, mating activities were no longer seen. The period of births following this mating season was the longest of the four birth seasons recorded, extending from March to November 1963. Each of the subsequent three mating seasons had a more pronounced peak and was followed by a more concentrated birth season. During the last 3 years of the study all births occurred between March and August and $74 \%$ of the births occurred during May and June.
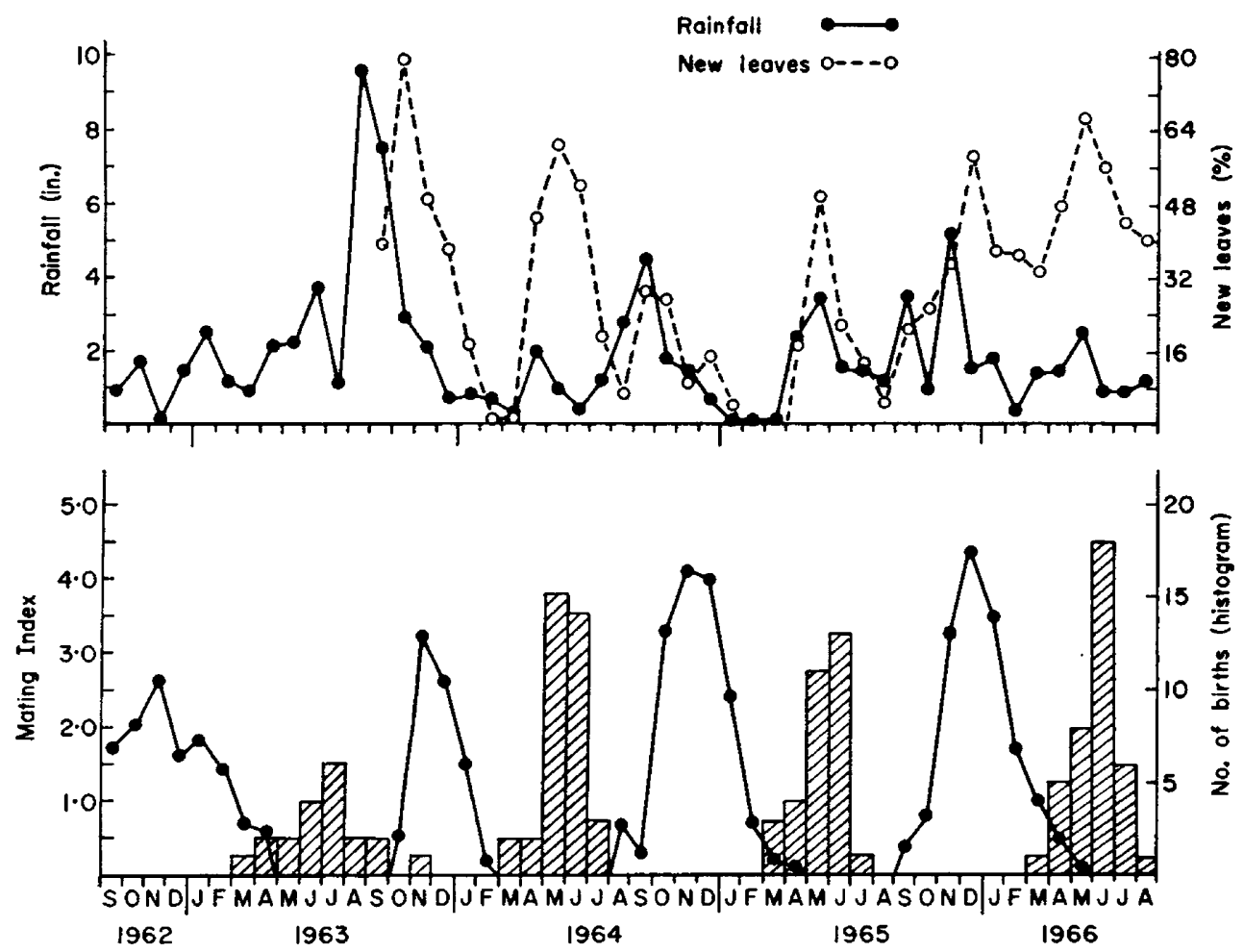

TEXT-FIG. 1. Month to month variation in rainfall, vegetation, mating activities and incidence of births in the free-ranging population of rhesus monkeys at La Parguera.

The upper portion of Text-fig. 1 represents the mean monthly rainfall during the 4-year period (September 1962 to August 1966) and the mean monthly percentage of plants showing new leaf growth during the last 3 years of the study. Each year, the heaviest rains fell during August, September and October and a minor peak occurred in April and May. The winter and midsummer months were extremely dry; usually less than 1 in. of rain fell each month. As expected, an increase in new vegetation followed the August to October rains, but the minor spring peak stimulated an almost equal increase in new vegetation.

Comparison of the rainfall and vegetation changes with cyclic mating and births shows that the late summer rains were followed approximately 1 to 2 months later by both an increase in new vegetation and the onset of mating behaviour. The secondary peak in rainfall occurred early in the birth season 
and the subsequent increase in new vegetation occurred during the peak of the birth season. It may be significant that the extraordinarily heavy rains during the late summer of 1963 were followed by the most concentrated mating and birth seasons. The very dry year of 1962 was followed by the least well-defined mating and birth seasons; however, the monkeys had just been released and the attendant social disruption (Vandenbergh, 1967) may have been responsible for the diffuse breeding pattern rather than the drought.

Other observed environmental factors on the island varied considerably less than the seasonal changes in rainfall. The mean of the summer temperatures (June to September) was $84^{\circ} \mathrm{F}$, only $8^{\circ}$ warmer than the mean of the winter temperatures (December to March). Changes in the length of daylight are similarly minor at the latitude of these islands, $18^{\circ} \mathrm{N}$. The longest day is only 2 $\mathrm{hr}$ and $17 \mathrm{~min}$ longer than the shortest day and the rate of change from one day to the next is slight, less than half a minute.

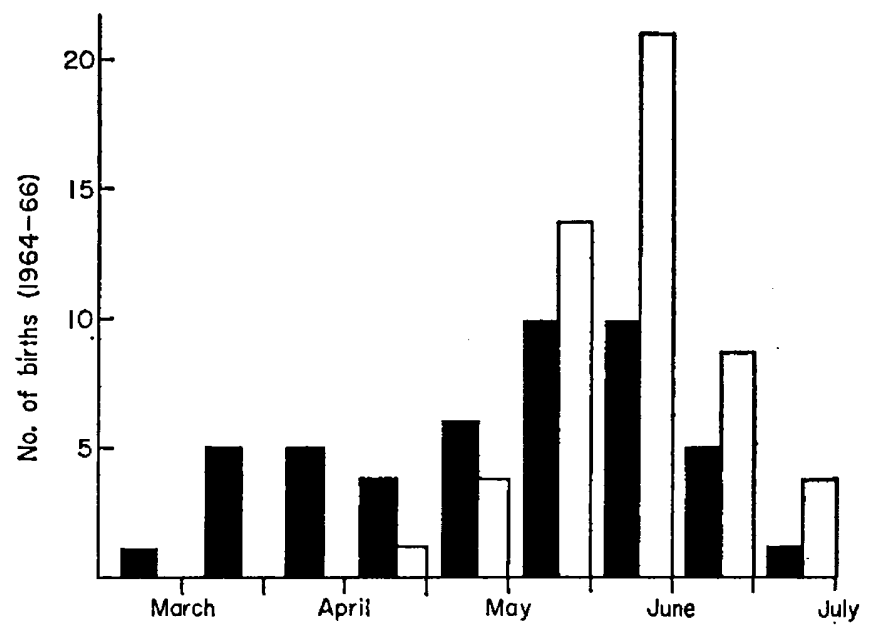

TexT-Fig. 2. Distribution of births to lactating (open columns, $\mathcal{N}=52$ ) and nonlactating (filled columns, $\mathcal{N}=47$ ) adult female monkeys.

The incidence of pregnancy among adult females (those over 3.5 years old) varied from $68 \%$ to $83 \%$ /year with a mean of $74.5 \%$ for the 4 -year study period. One female in each of the observed birth seasons was known to lose her foetus before term. These females, plus those that did not become visibly pregnant and those that lost an infant before the next mating season, were considered to be non-lactatingduring the mating season. In a number of cases the presence or absence of lactation was confirmed by examination of the mammae of females trapped at various times throughout the year. Females remained closely associated with their infant until the next was born, and lactated constantly if they gave birth each year. Non-lactating females gave birth significantly earlier than did lactating females $(P<0 \cdot 001$, Mann-Whitney $U$ test), indicating that lactation retarded the onset of mating activities (Text-fig. 2).

In addition to the previously noted cyclic changes in sexual behaviour, a seasonal variation in aggressive behaviour was seen in the colony. Quantified measures of agonistic activities were not made. However, since aggression often 
resulted in wounding, the variation in the frequency of wounds from mating to birth season provides a crude index of the levels of agonistic behaviour (Table 1). In each of the four comparisons between mating and birth seasons, a significantly higher proportion of males was wounded during the mating season than during the birth season. The frequency of wounding was considerably lower among females than males and in two of the four comparisons between

TABLE 1

PERGENTAGE OF ADULT MALE AND FEMALE MONKEYS WOUNDED IN THE LA PARGUERA COLONY DURING THE MATING AND BIRTH SEASON

\begin{tabular}{c|c|c|c}
\hline \multirow{2}{*}{ Season } & \multirow{2}{*}{$\begin{array}{c}\text { No. of } \\
\text { months }\end{array}$} & \multicolumn{2}{|c}{ Percentage wounded } \\
\cline { 3 - 4 } & & Male & Female \\
\hline 1962 to 1963 Mating & 7 & $26 \cdot 5$ & $12 \cdot 4$ \\
Birth & 6 & $5 \cdot 6^{*}$ & $5 \cdot 3^{*}$ \\
1963 to 1964 Mating & 5 & $14 \cdot 6$ & $5 \cdot 3$ \\
Birth & 5 & $0 \cdot 9^{*}$ & $2 \cdot 7$ \\
1964 to 1965 Mating & 7 & $8 \cdot 9$ & $4 \cdot 2$ \\
Birth & 6 & $3 \cdot 7^{*}$ & $1 \cdot 7$ \\
1965 to 1966 Mating & 7 & $20 \cdot 4$ & $10 \cdot 9$ \\
Birth & 5 & $5 \cdot 6^{*}$ & $4 \cdot 4^{*}$ \\
\hline
\end{tabular}

* Lower $(P<0.05)$ than preceding mating season $\left(\chi^{2}\right.$ test $)$.

seasons a significantly higher proportion of females displayed wounds during the mating season than during the birth period.

\section{DISGUSSION}

The seasonal rhythmicity of breeding in the La Parguera colony coincides well with the seasonal pattern of rainfall and subsequent vegetational changes. During each of 3 years for which complete data are available, mating activities began soon after the onset of late summer rains. The peak of mating behaviour occurred 2 to 3 months after the peak period of rainfall and coincided with the new growth of vegetation. This observed correlation does not demonstrate that a causal relationship exists between rainfall and breeding at La Parguera. It is, however, highly suggestive, especially since similar correlations have been reported for other populations of rhesus monkeys.

Information is available on two other populations of wild or free-ranging monkeys: those studied by Koford $(1965,1966)$ on Cayo Santiago, Puerto Rico, and by Southwick, Beg \& Siddiqi (1961, 1965) and Prakash (1962) in Northern India. A comparison of the seasonal patterns of rainfall, conceptions and births between the three locations where rhesus monkeys have been studied indicates that in all three locations the mating season occurs approximately 2 to 3 months after the onset of the rainy season (Text-fig. 3). Quantified observations of mating activity are not available for the Cayo Santiago and Northern Indian populations; hence, the mating season was calculated by back-dating $5 \frac{1}{2}$ months from the period during which at least $90 \%$ of the births occurred. Five and a half months represents the gestation period of the rhesus monkey (Hurme \& van Wagenen, 1953). 
Comparisons between Cayo Santiago and La Parguera are particularly pertinent because husbandry conditions are very similar in the two colonies. Cayo Santiago is a 37-acre island off the eastern coast of Puerto Rico containing approximately 600 monkeys at present. Variations in temperature and daylength are very similar to those at La Parguera. However, although only 100 miles east of La Parguera, Cayo Santiago's pattern of rainfall differs considerably from that at La Parguera. The dry season at Cayo Santiago begins in January and usually ends in April or May with the onset of heavy rains. Sporadic rains continue during the summer months and gradually decline during autumn. Mating activities begin on Cayo Santiago during July and August and apparently reach their peak during September and October. The

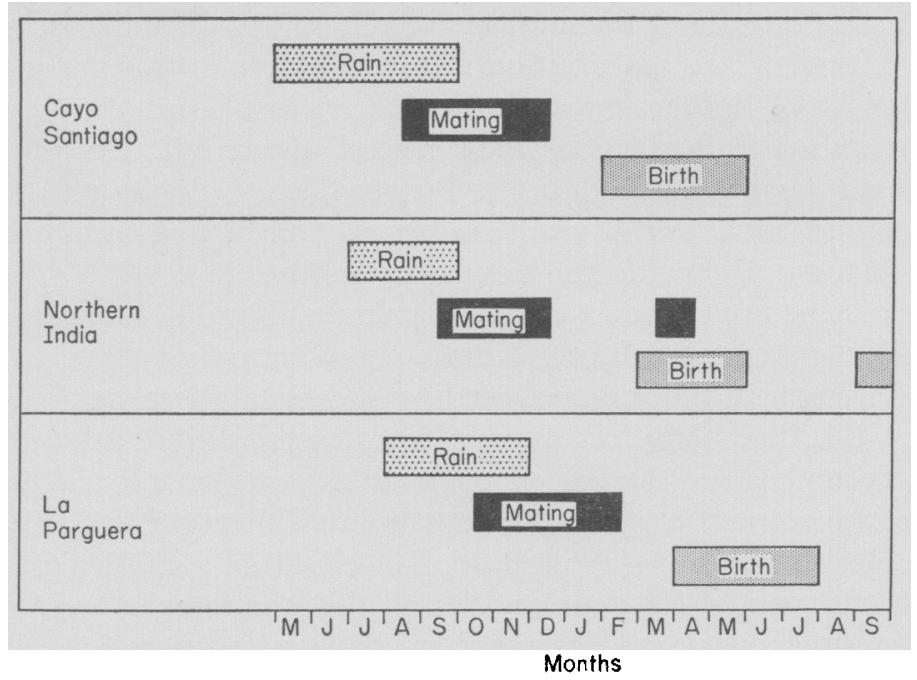

TEXT-FIG. 3. A diagram of the temporal relationship between seasonal rainfall and reproductive activities in three populations of rhesus monkeys. The parameters of the rain, mating and birth seasons are explained in the text.

restricted mating season is followed by a similarly restricted birth season. Of 365 births between 1960 and 1964, 94\% were born between February and May. In one year, 1961, the spring rains failed to arrive with their normal intensity and the following breeding season began 1 month later than in other years. Thus, the onset of both the rainy season and the mating season begins about $2 \frac{1}{2}$ months earlier at Cayo Santiago than at La Parguera.

On Cayo Santiago, males as well as females display a seasonal change in reproductive potency. The testes of adult and sub-adult male monkeys are largest during the mating season, decline in size as the mating season wanes and then increase in size again at the approach of the next mating season (Sade, 1964). Accompanying this change in size is an annual spermatogenic cycle showing cessation of spermatogenesis at the time of decreasing testis size and a subsequent return of spermatogenesis as the testes enlarge (Conaway \& Sade, 1965). Observations of male behaviour and sex skin indicate a similar situation at La Parguera.

The second area for which comparative information is available on the breeding of rhesus monkeys is within the natural geographic range of the 
species. In Northern India, the seasonal differences in temperature and daylength vary more than in either of the colonies near Puerto Rico. Southwick et al. (1961) collected information on the reproduction of monkeys living between $24^{\circ}$ and $31^{\circ} \mathrm{N}$ latitude in areas where temperature ranged from below freezing in winter to above $90^{\circ} \mathrm{F}$ in summer. Rainfall is confined almost entirely to the monsoon season, July to September. Based on the observations of Prakash (1962) and Southwick et al. (1961), newborn rhesus monkeys in this area are seen only from March to May and again in September and October. The absence of births between May and September probably represent a real hiatus rather than an inadequacy of data because Prakash apparently made continuous observations during this period without recording any births. By combining the data of both studies, the autumnal birth season was found to account for only $16 \%$ of the recorded births. This distribution of births indicates that most conceptions occur between mid-September and mid-December. Thus the period of conceptions occurs soon after the heaviest period of rainfall. However, northern India lies at a higher latitude than the Puerto Rican colonies and the resultant increase in the seasonal variation of environmental factors cannot be excluded as possible factors influencing the time of breeding.

Rhesus monkeys are the most common primate found in laboratories and are often bred for experimental use. Comparisons can thus be drawn between seasonal differences in laboratory breeding success and seasonal breeding patterns in the wild. Essentially two types of housing conditions are used in laboratories. The animals are either given access to the outdoors for variable periods of time in outdoor pens or they are kept isolated from natural environmental conditions. Both Hartman (1932) and Rowell (1963) studied monkeys kept outdoors at least part of the time and found that the females were anovulatory during the summer months (Hartman) or, at least, conceptions did not occur in groups containing adults of both sexes during this period (Rowell). On the other hand, Ponce de Lugo (1964) presented evidence that females held entirely indoors could conceive at any time of the year. Her data, however, do not indicate the relative amount of 'effort' required to produce a conception at various times of the year, i.e. the number of hours of pairing required to produce a conception in summer compared with a similar effort in winter. Nevertheless, such data do suggest that the more constant the environment of the monkey the greater will be its ability to mate at any season of the year.

\section{ACKNOWLEDGMENTS}

We wish to thank Mr V. Bracero for assistance in collecting data, Dr Carl B. Koford and Dr John A. Morrison for providing unpublished data on the Cayo Santiago population, and Dr Charles H. Southwick for reviewing the manuscript.

\section{REFERENCES}

Altmann, S. A. (1962) A field study of the sociobiology of rhesus monkeys, Macaca mulatta. Ann. N.Y. Acad. Sci. 102, 338.

BAKER, J. R. \& RANson, R. M. (1932) Factors affecting the breeding of the field mouse (Microtus agrestis). Part 1. Light. Proc. R. Soc. B, 110, 313.

Bissonnette, T. H. (1932) Modification of mammalian sexual cycles; reactions of ferrets (Putorius vulgaris) of both sexes to electric light added after dark in November and December. Proc. $R$. Soc. B, 110, 332. 
Bissonnette, T. H. \& Csech, A. G. (1939) A third year of modified breeding behavior with raccoons. Ecology, 20, 156.

CARpenter, C. R. (1942) Sexual behavior of free-ranging rhesus monkeys (Macaca mulatta). J. comp. Psychol. 33, 113.

ConawaY, C. H. \& SADE, D. S. (1965) The seasonal spermatogenic cycle in free-ranging rhesus monkeys. Folia Primatol. 3, 1.

FARNer, D. S. (1959) Photoperiodic control of annual gonadal cycles in birds. In: Photoperiodism and Related Phenomena in Plants and Animals, p. 717. American Association for the Advancement of Science, Washington.

FrITH, H. J. (1959) The ecology of wild ducks in inland New South Wales. IV. Breeding. CSIRO Wildl. Res. 4, 156.

Hartman, C. G. (1932) Studies in the reproduction of the monkey Macacus (Pithecus) rhesus, with special references to menstruation and pregnancy. Contr. Embryol. 134, 3.

Hinde, R. A. \& Roweld, T. E. (1962) Communication by postures and facial expressions in the rhesus monkey (Macaca mulatta). Proc. zool. Soc. Lond. 138, 1.

Hurme, V. O. \& van Wagenen, G. (1953) Basic data on the emergence of deciduous teeth in the monkey (Macaca mulatta). Proc. Am. phil. Soc. 97, 291.

Koford, C. B. (1965) Population dynamics of rhesus monkeys on Cayo Santiago. In: Primate Behavior: Field Studies of Monkeys and Apes, p. 160. Ed. I. DeVore. Holt, Rinehart \& Winston, New York.

Koford, C. B. (1966) Population changes in rhesus monkeys: Cayo Santiago, 1960-1964. Tulane Stud. Zool. 13, 1.

Lancaster, J. B. \& Lee, R. B. (1965) The annual reproductive cycle in monkeys and apes. In: Primate Behavior, p. 486. Ed. I. DeVore. Holt, Rinehart \& Winston, New York.

Marshall, A. J. \& Disney, H. J. De S. (1957) Experimental induction of the breeding season in a xerophylous bird. Nature, Lond. 180, 647.

Marshall, A. J. (1961) Reproduction. In: Biology and Comparative Physiology of Birds, p. 169. Ed. A. J. Marshall. Academic Press, New York.

Orians, G. H. (1960) Autumnal breeding in tricolored blackbirds. Auk, 77, 379.

Orsche, A., Laws, D. L., Kamemoro, F. E. \& Farner, D. S. (1959) The hypothalamo-hypophyseal neurosecretory system of the white-crowned sparrow, Zonotricha leucophrys gambelli. Z. Zellforsch. mikrosk. Anat. 51, 1.

Ponce De Lugo, C. G. (1964) Length of menstrual cycles in reference to time of successful mating in Macaca mulatta. Biologia Neonat. 6, 104.

Poole, W. E. (1960) Breeding of the wild rabbit. Oryctolagus cunicus (L.) in relation to the environment. CSIRO Wildl. Res. 5, 21.

Prakash, I. (1962) Group organization, sexual behaviour and breeding season of certain Indian monkeys. Fap. F. Ecol. $12,83$.

Rowell, T. E. (1963) Behaviour and female reproductive cycles of rhesus macaques. F. Reprod. Fert. 6, 193.

Rowan, W. (1925) Relation of light to bird migration and developmental changes. Nature, Lond. 115, 494.

SADE, D. S. (1964) Seasonal cycle in size of testes of free-ranging Macaca mulatta. Folia Primat. 2, 171.

Serventy, D. L. \& Marshall, A. J. (1957) Breeding periodicity in Western Australian birds. Emu, $57,99$.

Southwick, C. H., BEG, M. A. \& SiddieI, M. R. (1961) A population survey of rhesus monkeys in Northern India. II. Transportation routes and forest areas. Ecology, 42, 699.

Southwick, C. H., BEG, M. A. \& Sidpror, M. R. (1965) Rhesus monkeys in Northern India. In: Primate Behavior, p. 111. Ed. I. DeVore. Holt, Rinehart \& Winston, New York.

VANDENBERGH, J. G. (1967) The development of social structure in free-ranging rhesus monkeys. Behaviour, 29, 179. 